\title{
Multilayer Perovskite-Based Thermistors Fabricated by LTCC Technology
}

\author{
J. Kulawik, D. Szwagierczak, K. Witek, A. Skwarek And B. Gröger \\ Institute of Electron Technology, Kraków Division, Zabłocie 39, 30-701 Kraków, Poland
}

\begin{abstract}
In this work, single-phase $\mathrm{La}_{0.7} \mathrm{Sr}_{0.3} \mathrm{Zr}_{0.5} \mathrm{Co}_{0.2}^{2+} \mathrm{Co}_{0.3}^{3+} \mathrm{O}_{3}$ and $\mathrm{La}_{0.8} \mathrm{Sr}_{0.2} \mathrm{Ti}_{0.5} \mathrm{Co}_{0.3}^{2+} \mathrm{Co}_{0.2}^{3+} \mathrm{O}_{3}$ ceramics with the stable perovskite structure were utilized for fabrication of multilayer negative temperature coefficient thermistors. The number and thicknesses of ceramic layers were adjusted to attain suitable resistances in a desired temperature range. Scanning electron microscopy studies revealed a dense, fine-grained microstructure of ceramic layers, lack of delaminations and cracks at ceramic layer-conductive layer boundaries and a good cooperation with conductive layers. The temperature coefficients of resistance of the fabricated multilayer thermistors were changing from -13 to $-1 \% / \mathrm{K}$ in the temperature range from -55 to $400{ }^{\circ} \mathrm{C}$.
\end{abstract}

DOI: 10.12693/APhysPolA.123.436

PACS: 84.32.Ff, 81.05.Mh, 85.40.Xx

\section{Introduction}

Thermistors are resistors with a high temperature coefficient of resistivity (TCR):

$$
\mathrm{TCR}=\frac{\mathrm{d} R_{T}}{R_{T} \mathrm{~d} T} .
$$

Due to their low cost, simple construction, high sensitivity and high signal to noise ratio thermistors are utilized for precise temperature measurement and control. The most widely used are negative temperature coefficient (NTC) thermistors made of semiconducting ceramics with the spinel or the perovskite structure. Thermally activated polaron hopping is a mechanism responsible for the electrical conduction of these materials. Their resistance $R_{T}$ changes exponentially with temperature $T$ and can be described by the relationship

$$
R_{T}=R_{0} \mathrm{e}^{\frac{B}{T}} .
$$

The $B$ constant (beta factor or coefficient of thermal sensitivity) is a thermistor parameter which reflects how rapid is a resistance change with changing temperature. The value of $B$ constant can be determined on the basis of the following formula:

$$
B=\frac{T_{1} T_{2}}{T_{2}-T_{1}} \ln \frac{R_{1}}{R_{2}},
$$

where $R_{1}$ and $R_{2}$ - resistances at temperatures $T_{1}$ and $T_{2}$, respectively.

Conventional NTC thermistors are based on spinel forming oxides of manganese, chromium, cobalt, copper, iron, nickel [1-4]. However, at temperatures exceeding $200{ }^{\circ} \mathrm{C}$, due to not stable composition and structure and resulting remarkable aging [5], the applicability of the spinel based materials is limited. Thus at higher temperatures, materials with the more stable perovskite structure are preferred [5-9]. Thermistors are produced as discrete bulk elements and as thick films screen printed on inert substrates. Recently, thick film thermistors fired on the surface or buried inside multilayer LTCC substrates have been also investigated [4].

The paper reports on the fabrication procedure, microstructure and the resistance-temperature characteristics of multilayer thermistors based on tape cast $\mathrm{La}_{0.7} \mathrm{Sr}_{0.3} \mathrm{Zr}_{0.5} \mathrm{Co}_{0.2}^{2+} \mathrm{Co}_{0.3}^{3+} \mathrm{O}_{3}$ and $\mathrm{La}_{0.8} \mathrm{Sr}_{0.2} \mathrm{Ti}_{0.5} \mathrm{Co}_{0.3}^{2+} \mathrm{Co}_{0.2}^{3+} \mathrm{O}_{3}$ ceramics with the perovskite structure cosintered with platinum contacts.

\section{Experimental}

Solid state reaction method was used to synthesize two perovskite materials with the composition $\mathrm{La}_{0.7} \mathrm{Sr}_{0.3} \mathrm{Zr}_{0.5} \mathrm{Co}_{0.2}^{2+} \mathrm{Co}_{0.3}^{3+} \mathrm{O}_{3} \quad$ (LSZC) and $\mathrm{La}_{0.8} \mathrm{Sr}_{0.2} \mathrm{Ti}_{0.5} \mathrm{Co}_{0.3}^{2+} \mathrm{Co}_{0.2}^{3+} \mathrm{O}_{3}$ (LSTC). Starting oxides and $\mathrm{SrCO}_{3}$ were weighed in appropriate proportions, ball-milled in isopropyl alcohol, dried, pelletized and calcined at $1250-1300{ }^{\circ} \mathrm{C}$ for $10 \mathrm{~h}$. The reaction products were ball milled for $8 \mathrm{~h}$ and dried. The perovskite LSTC and LSZC powders were utilized as inorganic components of slurries for tape casting and subsequently for fabrication of multilayer thermistors. The organic part of the slurries for tapes comprised polyvinyl butyral as a binder (ceramic:binder $=10: 1$ ), fish oil as a dispersant, polyethylene glycol and dibutyl phthalate as plasticizers (binder:plasticizers $=2: 1$ ), toluene and isopropyl alcohol as solvents. The inorganic and organic components of the slurries were mixed by ball milling for $4 \mathrm{~h}$. Fabrication of green foils from the prepared slurries was carried out by the use of a tape caster (R. Mistler). The thermistor tapes were dried at room temperature, and then at $50{ }^{\circ} \mathrm{C}$ for a few hours.

Further operations comprised cutting of green sheets, screen printing of internal contacts, stacking of thermistor sheets, isostatic lamination, dicing into individual thermistors, deposition of external terminations, and firing.

Green sheets with appropriate dimensions and holes for positioning were cut using a laser (Oxford Laser). Internal and external contacts were made of ESL Pt 5542 paste. Five or ten layers with screen printed internal contacts separated by 1-3 layers of the thermistor foil were stacked using a laboratory stacker and laminated in an isostatic laminator (Pacific Trinetics Corp.) under a 
pressure of $40 \mathrm{MPa}$ at $75^{\circ} \mathrm{C}$ for $10 \mathrm{~min}$. Then, dicing of the laminates into individual thermistors and deposition of external contacts were performed.

The final step was firing of multilayer thermistors in a chamber furnace according to a profile which ensured slow burnout of organic components in the temperature range $80-460{ }^{\circ} \mathrm{C}$ and cosintering of ceramic and $\mathrm{Pt}$ internal conductive layers at peak temperature of 1150 $1300{ }^{\circ} \mathrm{C}$ for $5 \mathrm{~h}$.

Parallel arrangement of thermistor layers makes possible to diminish the total resistivity of an element and to tailor the resistance to a desired range by adjusting the number of the layers. The resistance measurements were carried out in the temperature range from -55 to $400^{\circ} \mathrm{C}$. The microstructure of the ceramic layers and their compatibility with $\mathrm{Pt}$ contacts were investigated using a scanning electron microscope (FEI Co.).

\section{Results and discussion}

The obtained green tapes are smooth, flexible, with high strength, without cracks, bubbles or inclusions. The thickness of green tapes was about $80 \mu \mathrm{m}$. Figure 1a and $b$ shows a rolled flexible green thermistor tape and two kinds of green sheets with screen printed internal Pt contacts.
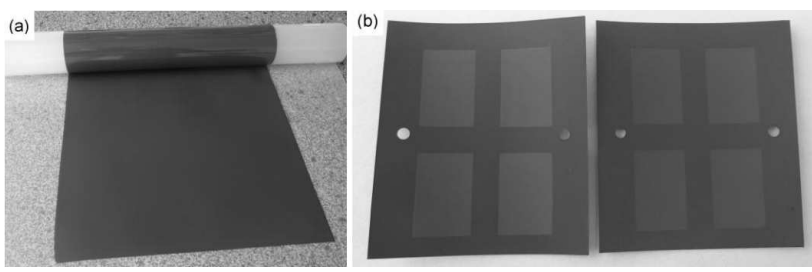

Fig. 1. (a) Flexible LSTC thermistor green tape, (b) green LSZC and LSTC thermistor sheets with screen printed Pt electrodes and laser cut holes for positioning.

In Fig. 2a the scheme of a multilayer thermistor is shown. Figure $2 \mathrm{~b}$ presents a multilayer thermistor after sintering.

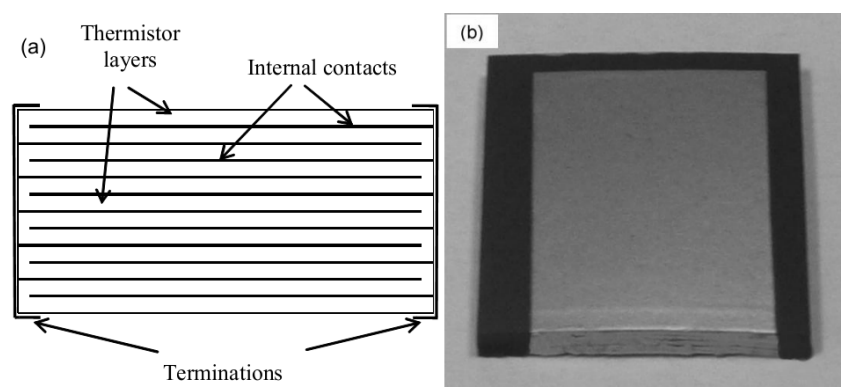

Fig. 2. (a) Schematic view of multilayer thermistor, (b) LSTC multilayer thermistor after sintering.

Figure 3 illustrates dense, fine-grained microstructure of thermistor layers, their good cooperation with conductive $\mathrm{Pt}$ layers as well as a lack of delaminations and cracks or inclusions of secondary phases at ceramic-conductor interfaces.
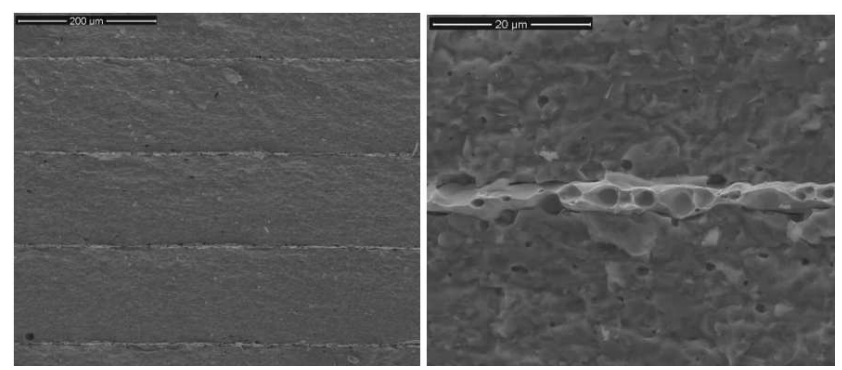

Fig. 3. SEM images of a fractured multilayer LSTC thermistor with platinum internal contacts.

In Fig. 4 the resistivity-temperature characteristics of the investigated perovskite materials (a) and their temperature coefficients of resistivity (b) are depicted in the temperature range from -55 to $400^{\circ} \mathrm{C}$.

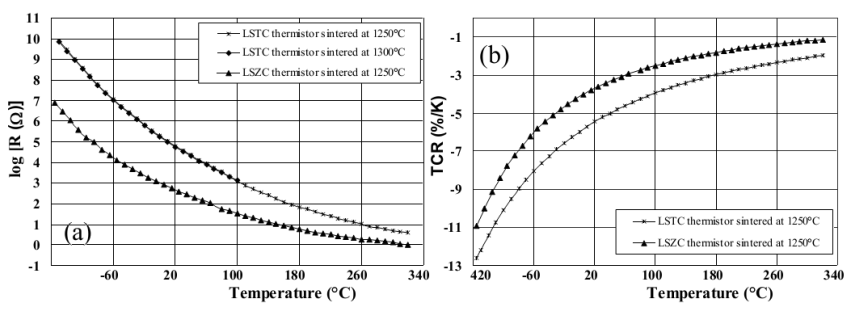

Fig. 4. Variation of resistance (a) and temperature coefficient of resistance (b) of a multilayer LSTC thermistor in the temperature range from -55 to $400{ }^{\circ} \mathrm{C}$.

The fabricated multilayer thermistors exhibit proper resistance ranges and high temperature coefficients of resistance. In the temperature range from -55 to $400{ }^{\circ} \mathrm{C}$, the TCR values are changing from -12.6 to $-2 \% / \mathrm{K}$ and from -11.0 to $-1.1 \% / \mathrm{K}$ for LSTC and LSZC thermistors, respectively. The calculated values of $B$ constant are ranging from 6300 to 8000 and 4200 to 5100 in this temperature range for LSTC and LSZC thermistors, respectively. A maximum of the coefficient of thermal sensitivity is observed which reaches for $B_{150 / 250}{ }^{\circ} \mathrm{C}$ the values equal to $8900 \mathrm{~K}$ and $5700 \mathrm{~K}$ for LSTC and LSZC thermistors, respectively. The activation energies of electrical conduction for the examined thick films were $0.6-0.7 \mathrm{eV}$. The changes in resistance of the thermistors after storing at room temperature during 3 months were negligible.

\section{Acknowledgments}

The work has been financed by the Polish Ministry of Science and Higher Education under grant $\mathrm{N}$ N507468038. 


\section{References}

[1] A. Feltz, W. Pölzl, J. Eur. Ceram. Soc. 20, 2353 (2000)

[2] M. Lee, M. Yoo, Sensor Actuat. A 96, 97 (2002)

[3] S. Jagtap, S. Rane, S. Gosavi, D. Amalnerkar, J. Eur. Ceram. Soc. 28, 2501 (2008).

[4] M. Hrovat, D. Belavic, J. Kita, J. Holc, J. Cilenšek, S. Drnovšek, J. Eur. Ceram. Soc. 29, 3265 (2009)

[5] A. Felz, J. Eur. Ceram. Soc. 20, 2367 (2000).
[6] D. Houivet, J. Bernard, J.M. Haussone, J. Eur. Ceram. Soc. 24, 1237 (2004).

[7] A. Veres, J.G. Noudem, S. Fourrez, G. Bailleul, Solid State Sci. 8, 137 (2006)

[8] Y. Luo, X. Liu, G. Chen, J. Alloys Comp. 429, 335 (2007)

[9] J. Kulawik, D. Szwagierczak, B. Gröger, A. Skwarek, Microelectron. Int. 24, 14 (2007) 